\title{
Research and Development Status of Grouted Splice Sleeve in Precast Concrete Structure
}

\author{
Ying Chang WU, Liu Peng SHENG, Wei Jian ZHAO \\ School of Civil Engineering, Shenyang Jianzhu University, Shenyang 110168, China
}

\begin{abstract}
The development of precast concrete structure is an effective way to promote industrialization of construction industry and housing industrialization, and is also a inevitable choice for green development. Grouted splice sleeve connector, regarded as one of the key technologies of precast concrete structure, has the advantages of high strength and good seismic performance. In this paper, the development of grouted splice sleeve connector is systematically summarized both home and abroad, existing problems in the domestic research of sleeve are evaluated and analyzed, and corresponding countermeasures are also further proposed.
\end{abstract}

\section{Introduction}

Compared with cast-in-place concrete structure, precast concrete structure has many advantages such as high efficiency,high quality, energy saving and environmental protection and so on. To achieve sustainable development in economic, environmental and social benefits, it rises gradually as a new structure system in China. Precast concrete structure is mainly made up of precast components, through the process of on-site assembly and connection. Previous investigation showed that connection failure between those components is the main reason to the collapse of the whole building[1]. The bearing capacity of building structures is directly affected by connecting quality, and the most critical part is undoubtedly the reinforced bar connection between the precast components.

Grouted splice sleeve was invented by Alfred A. Yee in late 1960 and first used for joining reinforcement bars of columns in 38 Ala Moana hotel (Honolulu, Hawaii). Then the patent of grouted sleeve connector was acquired by Japan TTK. Over the next several years, lots of improvements had been made to improve its effectiveness in Japan and North American. It was listed as a major reinforced bar connection technology in the report of the American Concrete Institute in 1983.In 1986, the work to develop the x-type sleeve was successfully completed. A large number of experimental studies and oretical analysis was conducted on it in Japan and America. Through a series of real seismic tests,It had also been proved reliable enough that can be used for high-rise construction even for ultra-high-rise concrete building. In china, many experiments had also been conducted to study this technology in the past decade. Lots of important data was obtained and some relevant specifications were also published to provide technical support for it. Now the sleeve was gradually applied to the actual projects.

\section{Research and Development Status of Grouted Sleeve Connector in Foreign Countries}

Grouted splice sleeve connector can be defined as a connection system using non-shrinking high strength grout to splice two discrete reinforced bars to ensure continuity during stress transmission[2]. Depending on the bond-slip resistance between the reinforced bars and the grout, it provides resistance to prevent reinforced bars pulling out from the sleeve. According to the connection type of reinforced bar and the sleeve, it can be divided into two groups: full-grouted splice sleeve, half-grouted splice sleeve.

\subsection{Current Development of Full-Grouted Splice Sleeve.}

Full-grouted splice sleeve can also be divided into two types from it's function: vertical full-grouted splice sleeve and horizontal full-grouted sleeve. The first kind of sleeve is applied to reinforced bar connection between precast components such as wall to wall or column to column, see Fig. 1. The second kind of sleeve is often used for reinforced bar connection between precast components such as beam to beam, see Fig. 2. Full-grouted ductile Iron sleeve connector is widely used in earthquake-prone place such as Japan and Taiwan. The length of such sleeve is slightly longer than half-grouted splice sleeve, but it has many advantages such as reliable load transferring, good toughness and energy absorption effect, which are helpful to resist earthquakes. This technology is becoming more and more perfect through

* Corresponding author: 1187562430@qq.com 
continuous research and improvement. NMB Japanese company and Tokyo Steel company are more skilled at this technology. Full-grouted sleeve connector produced by Tokyo Steel company was applied to The Vanke

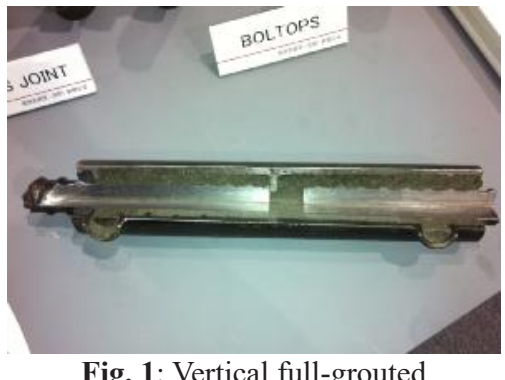

Fig. 1: Vertical full-grouted sleeve connector in Japan

Since shear keys of the sleeve are complex and difficult to machine, grouted splice sleeve is made of ductile iron both in the United States and Japan. As for this sleeve, despite the fact that production process has been very mature, technicians still continue to improve the technology. Combined with research and

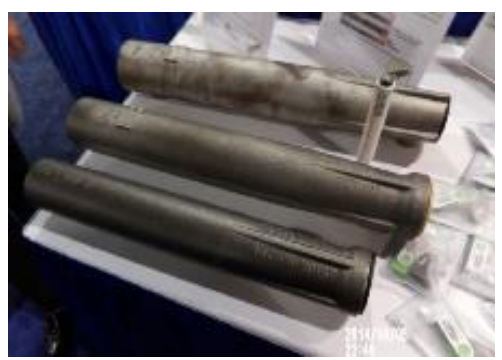

Fig. 3: NMB sleeve in Japan

\subsection{Current Development of Half-Grouted Splice Sleeve. 2.3 Parametric Studies}

Connection mechanism: firstly, prepare for processing internal threaded at one end of sleeve; secondly, prepare for processing external thread at one end of the bar; and then connect the bar to the sleeve[3]; finally, at the other end of the sleeve, connect them together by pouring grout materials into the sleeve. This type of connection is a composite form of straight thread connection and grouting connection. It was mostly used for reinforced bar connection between components such as wall to wall

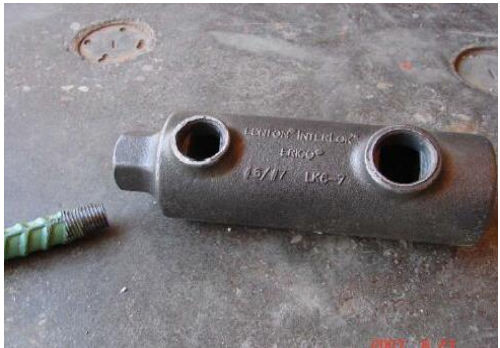

Fig. 5: Half-grouted sleeve connector in US

\section{Research and Development Status of Grouted Splice Sleeve in China}

Spring River which was regarded as the representative project in china. But due to high imports prices, this type of sleeve was not scaled up to wide use.

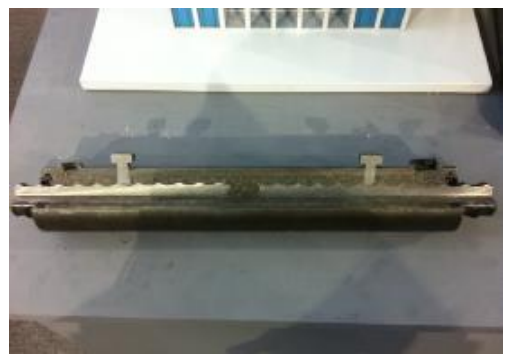

Fig. 2: Horizontal full-grouted sleeve connector in Japan development of ultra high strength grouting materials, Japan tends to develop thinner and shorter types of sleeve in the future, see Fig. 3. Right below (see Fig. 4)is a new squashed- cylinder shape sleeve invented by some company in the United States, two reinforced bars could be able to connected side by side through the sleeve.

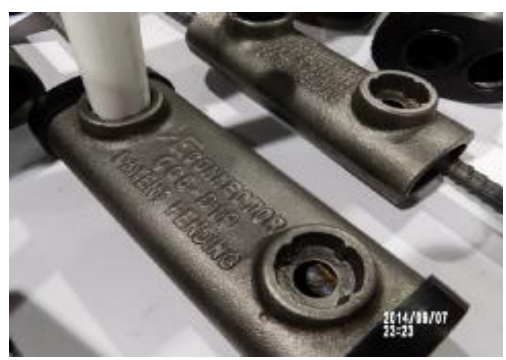

Fig. 4: Bar splicing sleeve in US

or column to column. Cross-sectional dimensions of this sleeve produced by the company Lenton Interlok was slightly larger. It's material was Ductile Iron. In order to clamp the sleeve firmly when connecting bar and sleeve together, hexagonal structure form was utilized in the threaded end of the sleeve, see Fig. 5. Japan's Tokyo Steel companies have similar half-grouted sleeve connector, see Fig. 6. What makes it different is the special external screw bar at the corresponding threaded end of the sleeve. The reinforced bar can be directly screwed into the threaded end of the sleeve, The gap between the two will be filled by pouring grout .

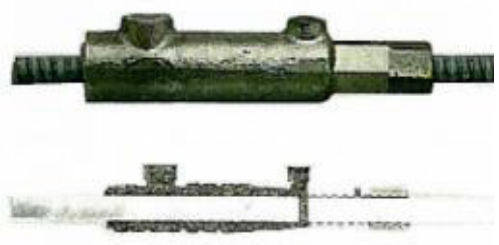

Fig. 6: Half-grouted sleeve connector in Japan

3.1 Current Development of Full-Grouted Splice Sleeve.

Zheng Yongfeng[4]developed grouted deformed pipe 
splice(GDPS sleeve) with standard seamless steel tube through cold rolling operation, see Fig. 7.And five coupler specimens were prepared and tested under incremental tensile load. The results show that if the anchorage length equals to eight times of the bar diameter, bar fracture failure mode can be achieved, see Fig. 8. and the ultimate tensile strength of the splices does meet the requirement for Class I splice. The inner cavity of sleeve structure of the grouted sleeve has a significant influence on the confining mechanism sleeve

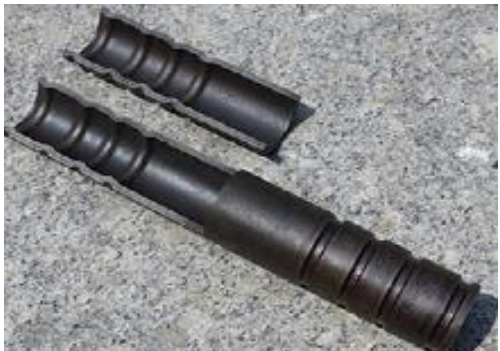

Fig. 7: GDPS sleeve

\subsection{Current Development of Half-Grouted Splice Sleeve}

When PC market had just started in China, due to the high cost of molding for nodular iron sleeve, faulty materials and expensive imported sleeve, so Vanke and Beijing Jian Mao used solid steel with the method of machining, produced China's first generation of

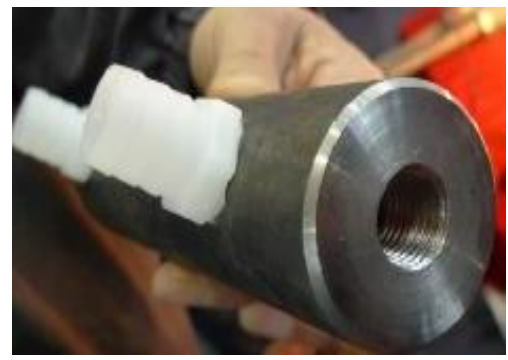

Fig. 9: The threaded end

On the basis of sleeve produced by Beijing Jianmao, a new type of sleeve named split half-grouted splice sleeve was developed by Beijing Building Construction Research Institute, see Fig.11. The cylindrical tube body was made of low alloy thick-walled steel tube. some shear keys were machined in the inner wall of steel tube, and internal threads were processed at one end of the sleeve. Middleware (see Fig. 12) with internal and external threads was screwed into the cylinder thread

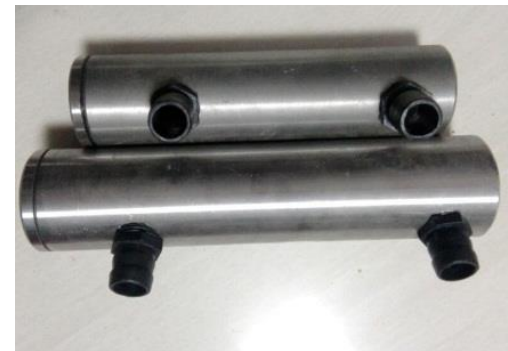

Fig. 11: Split half-grouted sleeve connector and strain distribution. The deformed section and smooth section of the sleeve show different strain distribution rule. However, due to the limitation of cold rolling operation, the distance from the first ring of the convex to the port of the sleeve is slightly larger, resulting in grouting material splitting easily at the port. In addition, the circular rib is shaped like a snakeskin tube. Deformation of the sleeve is very large under large deformation and high stress of the repeating of tension and compression, leading to joint stiffness degradation.

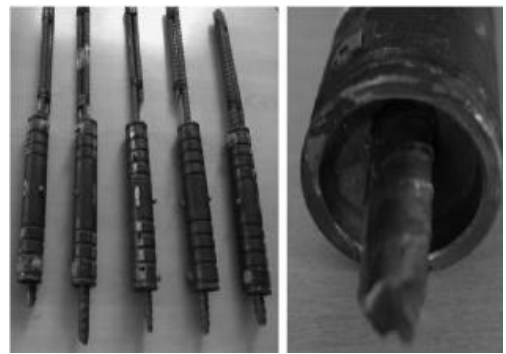

Fig. 8: Bar fracture

half-grouted splice sleeve, see Fig. 9and Fig. 10. This sleeve had been applied to many engineering applications such as Half-step bridge Beijing Public Security Bureau. Although meeting the needs of the market at that time, the machining methods also had some disadvantages such as difficult machining procedures, more waste materials, insufficient production costs.

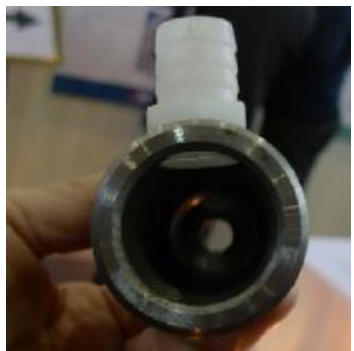

Fig. 10: The inner cavity structure

ends, thus forming a half-grouted sleeve connector. In order to reduce material waste and the difficulty of processing, the solid steel bar is replaced by the steel pipe. However, this type of sleeve has two disadvantages: (1)a hidden peril of quality might be added because of threaded connection between middleware and tube body;(2)producing middleware was also relatively cumbersome.

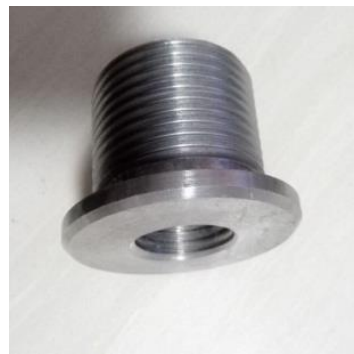

Fig. 12: Middleware 
With the development of the domestic PC market in recent years, nodular iron sleeve has also appeared on the market, see Fig.13. This type of sleeve has some circular convex ribs which are substantially similar to sleeve' in Japan. In order to avoid stress mutation between concrete and port of sleeve, variable cross-section form is machined at the threaded end. But it may lead to risk of fracture of the sleeve due to the stress concentration in

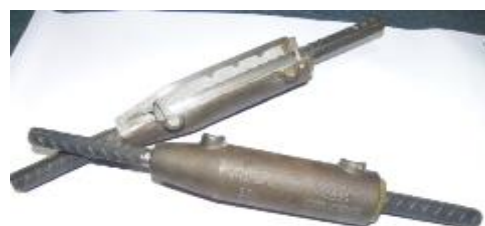

Fig.13: Nodular iron sleeve

\section{Problems \& Countermeasures}

As for grouted sleeve connection technology, the research on it starts relatively later in China and the relevant theoretical analysis and experimental study is insufficient. There are some problems in the theoretical study and practical application of prefabricated structures. The problems are as follows:

(1)The fundamental research on core technology of grouted sleeve is woefully inadequate both in quantity and depth. Although a number of experiments have been conducted mainly in domestic colleges and universities, these specimens mainly based on existed sleeve both home and abroad are tested through simple uniaxial tensile test to verify it's macro-performance. However, It is the insufficient fundamental research for Micro-stress transfer mechanism of the sleeve, failure mechanism, affecting relationship among dimension parameters that leads to the slow development of the optimization design of sleeve due to lack of theoretical basis.

(2)At present, domestic sleeve is developed mainly by mechanical metallurgy companies. However, it is insufficient to study it's connection performance and the effects on the whole structure. The development for grouted sleeve requires many disciplines such as materials, metallurgy, mechanical engineering and concrete structure and so on. But the ultimate goal is to serve for the concrete structure. How to meet production and construction requirements of concrete members on the basis of identity intensity of reinforced bars? What impact does increasing the local stiffness of splice have on the seismic behavior of concrete structures? From the perspective of structural engineering, These questions requires extensive research, and should be fed back into the design of grouted splice sleeve connector.

(3)Half-grouted sleeve connector is widely used in prefabricated concrete structure in china. However, it has many problems in the practical engineering. As for full-grouted sleeve connector, we lack comprehensive understanding and in-depth study. Compared with half-grouted sleeve connector, full-grouted sleeve variable cross-section. Taking into account the high cost of nodular iron and high technology content, there are also domestic manufacturers processing sleeve with steel, see Fig.14. Compared with nodular iron, cast steel has some disadvantages such as poor toughness, easy to get rust and lower energy absorption efficiency. Moreover, it's performance is not as good as nodular cast iron when experienced fatigue test and earthquake.

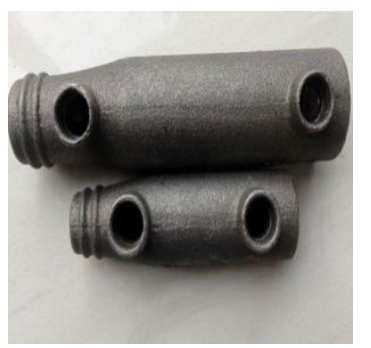

Fig. 14: Sleeve of steel casting

connector is longer and it's material consumption is a little larger. So the half-grouted sleeve connector with a relatively smaller size was developed at the start in china. As for this type of sleeve, there are many problems with its threaded end in practice. Firstly, It is not easy to control the number of threads which is screwed into the threaded end of sleeve at the construction site. Secondly, cross-section area of the reinforced bar is reduced due to the process of rib-stripped rolling straight thread. At the same time, stress concentration is more likely to happed at the thread end of sleeve when it is subjected to tension. Thirdly, Thread failure may also lead to reinforced bar pulling out.

In summary, on the basis of absorbing foreign experience and technology, much more attention should be paid to the fundamental research on grouted splice sleeve connector and core technology. it is of significance to develop and improve new sleeve which is suitable for our national situation. Meanwhile, establish and improve it's design theory, which have important theoretical and practical significance to future development of prefabricated concrete structure.

\section{References}

1. J.K.Iverson,N.M.Hawkins:Performance of Precast/Prestressed Concrete Building Structures During Northridge Earthquake, edited by PCI Jouranal(1994)

2. J.H.Ling, A. B. A. Rahman and I. S. Ibrahim: Tensile performance of grouted splice connectors in precast concrete structures(Precast Concrete Elements, Malaysia 2010)

3. W.X.Zhu,L.Shao,Y.Wang and W. Fu: Study on Semi-Grouting Coupler Connecting Technique for Steel Reinforcement(Architecture Technology,China 2015)

4. Y.F.Zheng,Z.X.Guo and Z.C.Sun: Experimental Study on the Behavior of Grouted Deformed Pipe Splice(Constuction Technology,China 2014) 